mento foi discutido com o departamento de Periodontologia da FMDUL, tendo-se estabelecido e proposto ao paciente uma abordagem em 3 fases: (i) restauração pré-endodôntica e pulpectomia (ii) alongamento coronário (iii) tratamento endodôntico e restauração. Vinte e seis meses apos conclusão do tratamento o paciente relatava ausência de sintomas, com manutenção da normalidades dos tecidos periapicais na radiografia de controlo. Discussão e conclusões: $\mathrm{O}$ alongamento coronário associado ao tratamento endodôntico constitui um passo viável, e muitas vezes necessário, para manutenção de dentes com pouca estrutura dentária supra-gengival remanescente. Neste caso em particular, a opção de manutenção do dente, apesar da extensa destruição deveu-se, por um lado, à idade do paciente, bem como a limitações económicas associadas a opção alternativa (extração e implante unitário). O planeamento conjunto entre Endodontista, Periodontologista e Prostodontista permitiu garantir a restaurabilidade do dente, respeitando o espaço livre biológico.

http://doi.org/10.24873/j.rpemd.2020.12.727

\section{\#003 Dens in Dent: caso clínico de um incisivo lateral}

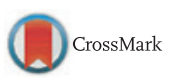

António Pedro Barbosa*, Álvaro Ferreira Rodrigues, Inês Vaz Silva, Sónia Viegas

\section{H. Vila Nova de Gaia Espinho}

Introdução: Dens in Dent (DiD) é uma malformação dentária caracterizada por uma invaginação revestida por esmalte da superfície da coroa e/ou raíz prévia à mineralização. A sua prevalência varia entre 0,3 e 10\%, sendo maior nos incisivos laterais, seguidos pelos incisivos centrais, em ambos os maxilares. Descrição do caso clínico: Apresentamos o caso de uma doente de 49 anos, sem antecedentes pessoais de relevo, medicada com anticoncecional oral. Há cerca de 5 anos teve um episódio de abcesso odontogénico em relação ao dente 2.2, com drenagem purulenta, que motivou tentativa de tratamento endodôntico radical (TER) há cerca de 3 anos pelo seu dentista assistente, sem sucesso por não ser possível obturar um segundo canal radicular (sic). Desde então assintomática, mantendo seguimento da lesão radiolucente periapical no dentista assistente, que recomendou a exodontia, motivando a referenciação ao Serviço de Estomatologia. Ao exame objetivo constatou-se que o dente 2.2 apresentava diâmetro mesiodistal maior que o contralateral, com restauração provisória classe I, sem dor à percussão e sem aumento da mobilidade. Observava-se orifício na mucosa vestibular entre os dentes 2.2 e 2.3 , compatível com trajeto fistuloso, sem drenagem ativa e sem dor à palpação. $\mathrm{Na}$ ortopantomografia não se objetivavam lesões e a zona correspondente ao segundo sextante apresentava artefactos de sobreposição. A radiografia retro-alveolar permitiu identificar uma lesão radiolucente periapical em relação com o dente 2.2, com uma aparente invaginação do esmalte, grosseiramente paralela ao longo eixo do dente, ultrapassando a junção amelocementária, o que permitiu o diagnóstico de DiD. Verificou-se ainda obturação incompleta dos canais ra- diculares. No caso apresentado, tendo em conta o mau prognóstico deste dente, devido ao grau de dificuldade do TER, e o risco de agravamento da perda óssea, optou-se pela extração do dente 2.2 e enucleação da lesão quística associada, sob anestesia local, que a doente aceitou com a indicação de reabilitação com implante à posteriori. Discussão e conclusões: A etiologia dos DiD mantém-se controversa, englobando causas como trauma, infeção e dismorfias celulares hiperplásicas. Perante o diagnóstico clínico de DiD, na ausência de sintomas ou sinais de doença pulpar, o tratamento de primeira linha consiste em selar a invaginação. Perante sinais e sintomas de infeção, o tratamento a adotar é o TER. Quando ineficaz, a cirurgia apical ou a extração dentária estão indicadas.

http://doi.org/10.24873/j.rpemd.2020.12.728

\section{\#004 Odontoma composto: caso clínico}

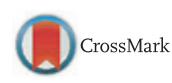

Ivan Cabo*, Maria das Dores Lopes, José Amorim, Jorge Ermida, José Pedro Figueiredo

Universidade de Coimbra- Faculdade de Medicina; Serviço de Estomatologia - Centro Hospitalar e Universitário de Coimbra

Introdução: Os odontomas são tumores odontogénicos benignos constituídos por tecidos dentários: esmalte, dentina e tecido pulpar. Geralmente são assintomáticos, detetados em achados radiográficos. A maioria dos odontomas têm um crescimento lento, devido ao seu desenvolvimento autolimitado; porém, ocasionalmente, podem atingir tamanhos consideráveis, causando expansão das corticais ósseas. Descrição de caso clínico: Doente do sexo feminino, de raça caucasiana, com 15 anos de idade, compareceu na Consulta de Estomatologia Pediátrica do Serviço de Estomatologia do Centro Hospitalar e Universitário de Coimbra. Tinha como antecedentes clínicos uma ventriculostomia endoscópica e ressecção cirúrgica de um tumor da glândula pineal (grau III), aos 14 anos. Sem medicação habitual. Ao exame físico não apresentava alterações de relevo. A ortopantomografia revelou a presença de uma lesão arredondada, entre as raízes dos dentes 32 e 33, formada por pequenas estruturas radiopacas semelhantes a dentes. Colocada a hipótese diagnóstica de odontoma composto, sob anestesia geral foi realizada a exérese cirúrgica da lesão, com acesso por vestibular, preservando as raízes adjacentes intactas. Confirmou-se o diagnóstico de odontoma composto, identificando-se 5 dentículos. Discussão e conclusões: Os odontomas, morfologicamente, podem ser classificados como complexos, quando se apresentam como massas irregulares contendo os diferentes tipos de tecidos dentários, ou como compostos quando esses tecidos dentários se organizam e formam pequenas estruturas semelhantes a dentes - designados de dentículos. Por vezes, os odontomas podem causar impactação, atraso ou desvio na erupção dos dentes definitivos. A etiologia dos odontomas é desconhecida; no entanto, fatores genéticos e causas ambientais locais (como como traumatismos ou infeções) têm sido propostos como possíveis causas. O tratamento de eleição para este tipo de lesões é a exérese cirúr- 